\title{
Recurrent Borderline Ovarian Surface Epithelial-Stromal Tumor
}

National Cancer Institute

\section{Source}

National Cancer Institute. Recurrent Borderline Ovarian Surface Epithelial-Stromal

Tumor. NCI Thesaurus. Code C115352.

The reemergence of borderline ovarian epithelial tumor after a period of remission. 